\title{
INTERFACING A GENERAL PURPOSE FLUID NETWORK FLOW PROGRAM WITH THE SINDA/G THERMAL ANALYSIS PROGRAM
}

\author{
Paul Schallhorn " and Daniel Popok** \\ * Sverdrup Technology, Inc. \\ Huntsville, AL \\ "* Network Analysis, Inc. \\ Huntsville, AL
}

\begin{abstract}
A B S T R A C T
A general purpose, one dimensional fluid flow code is currently being interfaced with the thermal analysis program SINDA/G. The flow code, GFSSP, is capable of analyzing steady state and transient flow in a complex network. The flow code is capable of modeling several physical phenomena including compressibility effects, phase changes, body forces (such as gravity and centrifugal) and mixture thermodynamics for multiple species. The addition of GFSSP to SINDA/G provides a significant improvement in convective heat transfer modeling for SINDA/G. The interface development is conducted in multiple phases. This paper describes the first phase of the interface which allows for steady and quasisteady (unsteady solid, steady fluid) conjugate heat transfer modeling.
\end{abstract}

\section{INTRODUCTION}

Accurate conjugate heat transfer predictions for complex situations require both proper modeling of the solid and flow networks and realistically modeling the interaction between these networks. Proper modeling of the solid network can be easily performed using either classical analytical techniques or with established numerical model tools, such as SINDA/G. Proper modeling of the flow network, however, requires a numerical tool that account for multiple different flow paths, a variety of flow geometries, an ability to predict flow reversal, the ability to account for compressibility effects and ability to predict phase change.

\section{THERMAL CODE}

SINDA $/ G^{1}$ (Systems Improved Numerical Differencing Analyzer / Gaski) is a code that solves the diffusion equation using a lumped parameter approach. The code was developed as a general purpose thermal analysis program which uses a conductor-capacitor network to represent a physical situation; however, SINDA can solve other diffusion type problems. The code consists of two components: a preprocessor and a library. The library consists of a series of subroutines necessary to solve a wide variety of problems. The preprocessor converts the input model deck into a driver FORTRAN source code, complies and links with the library, then executes the model and generates an output file. One of the main advantages of SINDA over other thermal codes is that it accepts FORTRAN statements, developed by the user, in the input deck which allow the user to tailor the code to suit a particular problem. It is this ability to add FORTRAN coding to the SINDA input deck which easily allows for an interface with other codes, specifically in the case at hand, a general purpose fluid network flow code.

\section{FLUID CODE}


The Generalized Fluid System Simulation Program ${ }^{2}$ (GFSSP) was developed for the Marshall Space Flight Center's Propulsion Laboratory for the purpose of calculating pressure and flow distribution in a complex flow network associated with secondary flow in a liquid rocket engine turbopump. The code was developed to be a general purpose, one-dimensional flow network solver so that generic networks could be modeled. Capabilities of the GFSSP are summarized below:

- Modeling flow distributions in a complex network;

- Modeling of compressible and incompressible flows;

- Modeling real fluids via embedded thermodynamic and thermophysical properties routines and tables;

- Mixing calculation of real fluids;

- Phase change calculation of real fluids;

- Axial thrust calculations for turbopumps;

- Calculation of buoyancy driven flows;

- Calculation of both steady and unsteady flows (both boundary conditions and geometry can vary with time);

- Choice of first or second law approach to solving the energy equation.

The GFSSP uses a series of nodes and branches to define the flow network. Nodes are positions within the network where fluid properties (pressure, density, etc.) are either known or calculated. Branches are the portions of the flow network where flow conditions (geometry, flow rate, etc.) are known or calculated. The code contains 18 various branch options to model different geometries. These branch options include classical pipe flow with and without end losses, flow with a loss coefficient, non-circular duct, thick orifice, thin orifice, square expansion, square reduction, face seal, labyrinth seal, valves and tees, pump using pump characteristics, pump using horsepower and efficiency, and a Joule-Thompson device.

The GFSSP has additional options including the ability to model gravitational effects, rotation, fluid mixture, a turbopump assembly, the ability to add mass, momentum and heat sources at any appropriate point in the model, and the ability to model multidimensional flow (two and three dimensional flow field calculation).

The GFSSP uses a finite volume approach with a staggered grid. This approach is commonly used in computational fluid dynamics schemes (Patankar ${ }^{3}$, Patankar and Karki ${ }^{4}$ ).

\section{OVERVIEW OF SOLID/FLUID INTERFACE}

In order to run the two codes concurrently, GFSSP was converted into a subroutine called from an interface subroutine. Figure 1 schematically illustrates the interface call sequence. This interface subroutine, called from SINDA, uses the surface temperature and area of the adjacent solid node along with the flowrate and upstream temperature of the adjacent fluid branch to calculate the heat exchange between the solid and fluid. The interface routine calculates, or has specified, the convective heat transfer coefficient $(h)$. The interface subroutine calculates and distributes the heat back to the solid node and to the downstream fluid node using a technique called "upwinding." Upwinding models the effect of heat addition to the fluid manifesting downstream of the point of the addition, from a bulk flow perspective. This technique is commonly used in CFD codes to model fluid inertia. Figure 2 illustrates the convective heat transfer calculation scheme. 


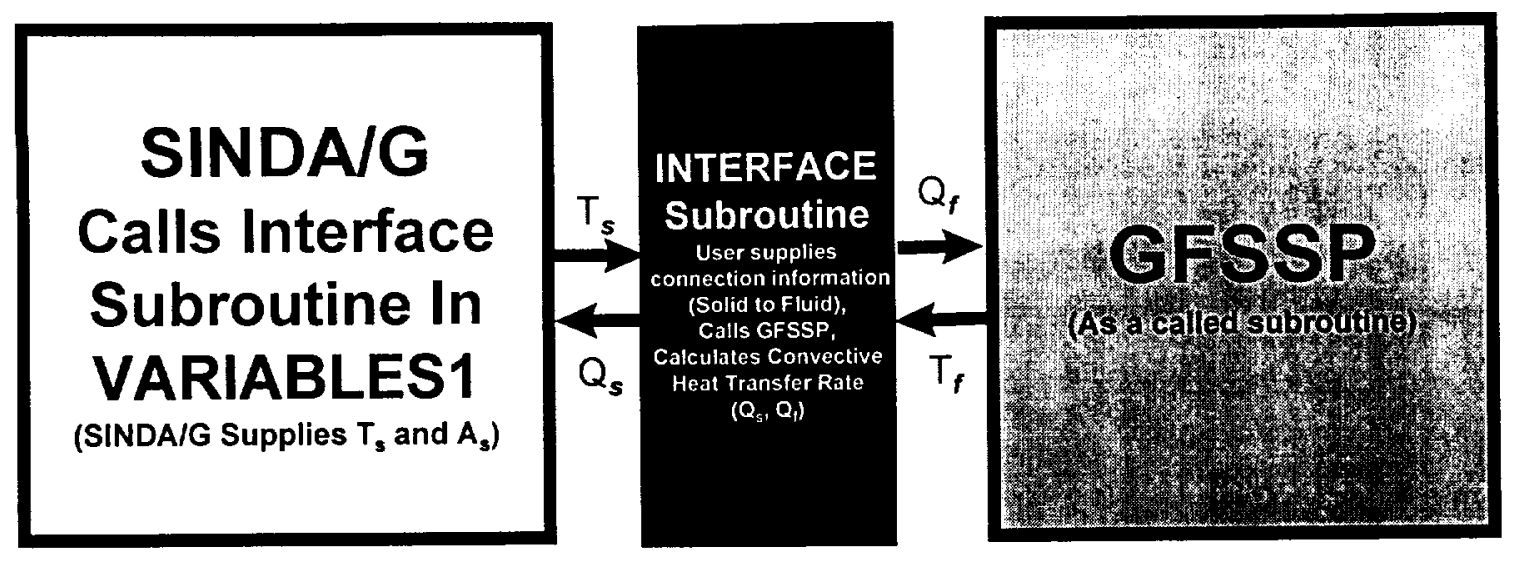

Figure 1: SINDA - GFSSP Interface
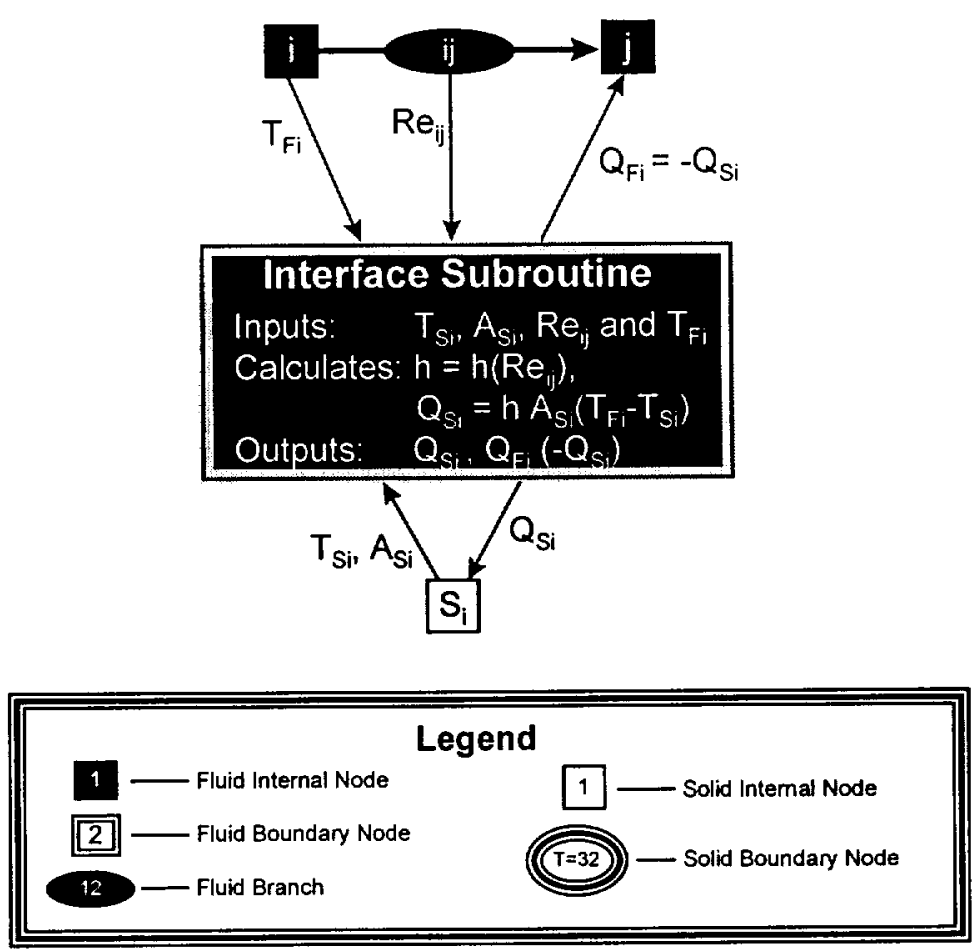

Figure 2: Convective Heat Transfer Scheme Within The SINDA - GFSSP Interface

From the point of view of the two codes involved, therefore, only heat sources/sinks are added at discrete nodes and these heat sources/sinks are updated with every SINDA iteration.

The interface is generalized so that the solid and fluid models can have different levels of discretization, resulting in three different scenarios: multiple solid nodes for a given fluid branch, one solid node for a given fluid branch, and one solid node for multiple fluid branches. These three scenarios are illustrated in Figure 3, below. 


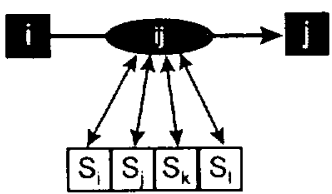

Multiple Solid Nodes for One Fluid Branch

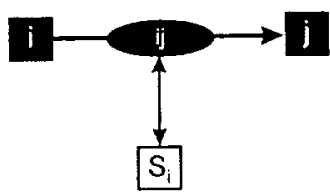

One Solid Nodes for

One Fluid Branch

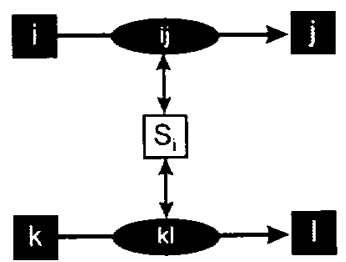

One Solid Node for Multiple Fluid Branches

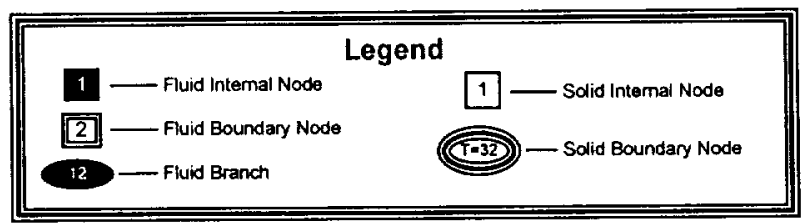

Figure 3: Possible Solid/Fluid Discretization Scenarios

The entire GFSSP common block has been placed into the interface subroutine to allow the user to update the fluid network at every iteration/time-step via this subroutine. The number of solid nodes that connect to the fluid network, the names, temperatures, areas exposed to the fluid network and corresponding heat sources are passed back and forth from SINDA/G and the interface subroutine.

\section{BENCHMARKING}

In order to debug and validate the interface, a simple textbook example was chosen as a benchmark case. The benchmark case is a circular rod between two walls with convective heat transfer. The walls are held at $32^{\circ} \mathrm{F}$ and $212^{\circ} \mathrm{F}$, respectively. The rod has a thermal conductivity of $9.4 \mathrm{BTU} / \mathrm{ft}-\mathrm{hr} \mathrm{C}^{\circ} \mathrm{R}\left(2.611 \times 10^{-3}\right.$ $\left.\mathrm{BTU} / \mathrm{ft}-\mathrm{sec}^{\circ} \mathrm{R}\right)$. The convective heat transfer coefficient between the rod and the fluid is $1.14 \mathrm{BTU} / \mathrm{ft}^{2} \mathrm{hr}{ }^{\circ} \mathrm{R}$ $\left(3.167 \times 10^{-4} \mathrm{BTU} / \mathrm{ft}^{2} \mathrm{sec}^{\circ} \mathrm{R}\right)$, with the fluid temperature set at $70^{\circ} \mathrm{F}$. The rod has a diameter of 2.0 inches $(0.167 \mathrm{ft})$ and has a length of $2.0 \mathrm{ft}$.

The SINDA/G model consists of 10 nodes -8 diffusion nodes and 2 boundary nodes. The GFSSP model consists of 5 nodes -3 internal nodes and 2 boundary nodes - and 4 branches. For every four nodes in the solid model, a corresponding fluid branch is assigned. Water was chosen as the working fluid with a sufficient pressure differential between the boundary nodes to supply a flowrate that would allow for an approximately constant temperature without appreciable temperature rise due to shear. The convection coefficient was provided directly to the interface so as to make a direct comparison to an analytical solution. The benchmark case and combined model is shown schematically in Figure 4. 

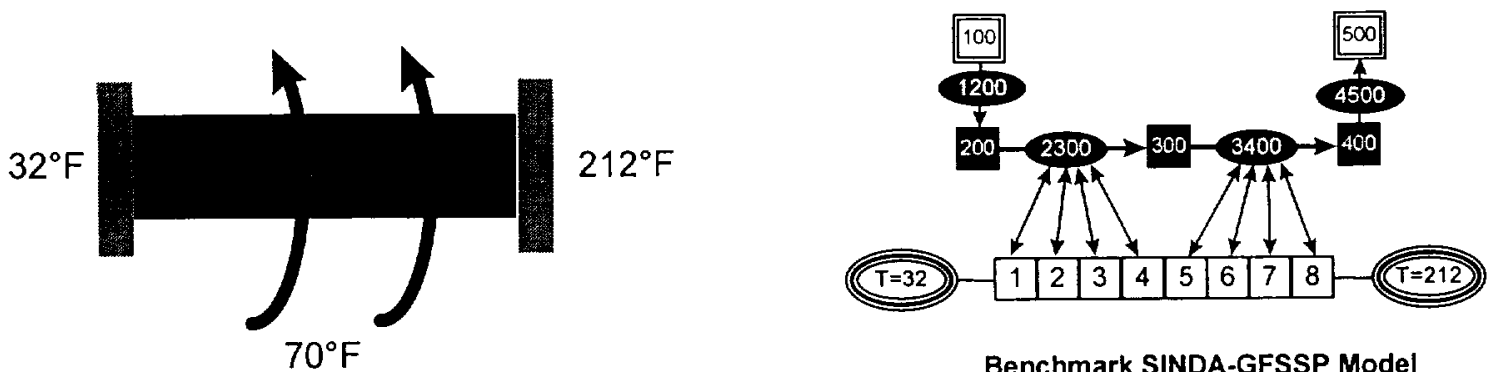

Benchmark Case

Benchmark SINDA-GFSSP Model

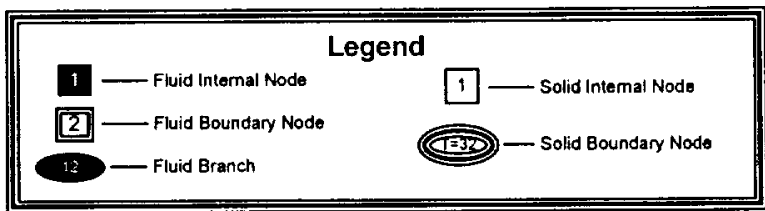

Figure 4: SINDA/G - GFSSP Benchmark Case

The closed form solution of the benchmark case is given in Equation 1, below, and derived in the Thermal Analysis Workshop 5 .

$$
\mathrm{T}(\mathrm{x})=\mathrm{T}_{\text {fluid }}+4.653 \mathrm{e}^{1.714 \mathrm{x}}-42.650 \mathrm{e}^{-1.714 \mathrm{x}}
$$

where, $\quad \mathrm{x}=$ distance from the cold wall in feet and

$\mathrm{T}_{\text {fluid }}=70^{\circ} \mathrm{F}$.

The results of the benchmark combined models are shown with the analytical solution in Figure 5 below. As Figure 5 illustrates, the SINDA/G - GFSSP interfaced prediction lies on the curve of the analytical solution, thus providing a first level validation of the interface.

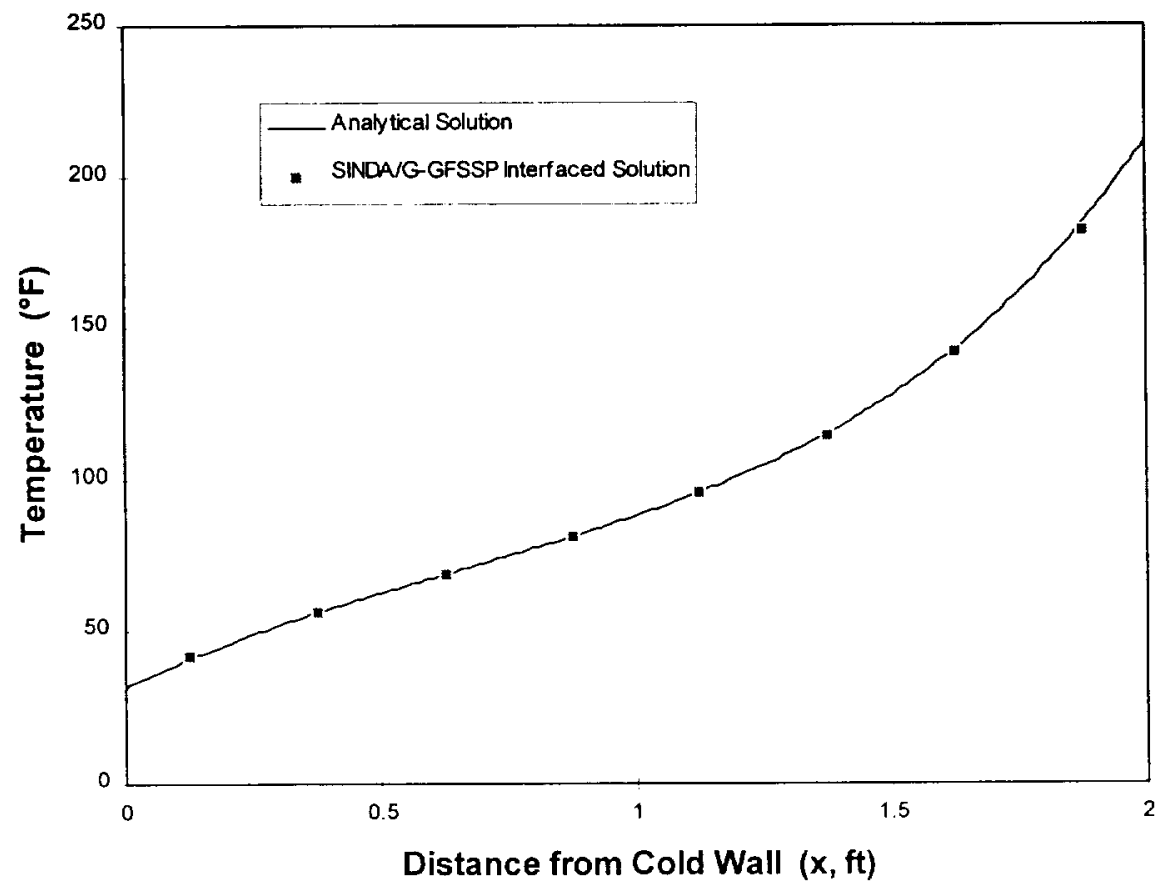


Figure 5: Benchmark Case Results for SINDA/G-GFSSP Model

with Analytical Solution

\section{ADDITIONAL TEST CASES}

In order to exercise the interface between SINDA/G and GFSSP, three additional test cases were identified which exploit different aspects of the interface.

The goal of the first of the additional test cases (the second test case) was to predict phase change in the fluid model due to heat transfer to the solid. In this case, steam at $215^{\circ} \mathrm{F}$ and 14.705 psia enters a flow path and flows over a solid bar and exits at 14.700 psia. The back face of the bar is held at $32^{\circ} \mathrm{F}$. For simplicity, the convective heat transfer coefficient is set in the interface at a constant value $\left(3.167 \times 10^{-3}\right.$ $\mathrm{BTU} / \mathrm{ft}^{2} \mathrm{sec}^{\circ} \mathrm{R}$, an order of magnitude higher than the benchmark case). It should be noted that. Figure 6 illustrates the physical situation and the SINDA/G - GFSSP combined models. The results of the modeling effort for case 2 is shown in Figures 7 and 8 . Figure 7 illustrates the temperature profile for both the solid and the fluid. Note that the temperature of the fluid remaining constant during the phase change. Figure 8 illustrates the quality of the fluid as a function of location downstream of the inlet. The fluid temperature is superimposed on this figure to show the constant temperature during the phase change.

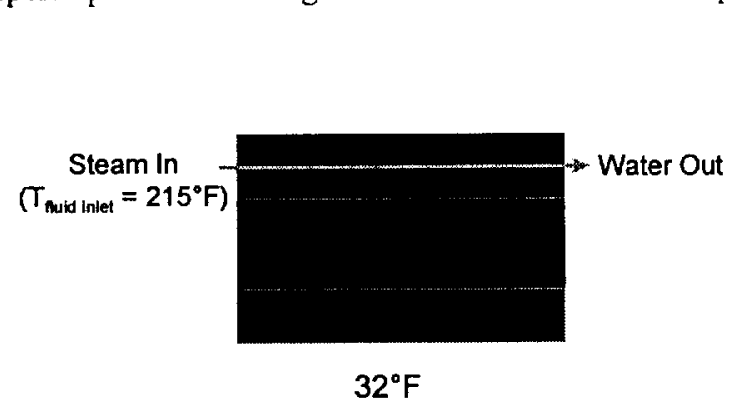

Physical Situation
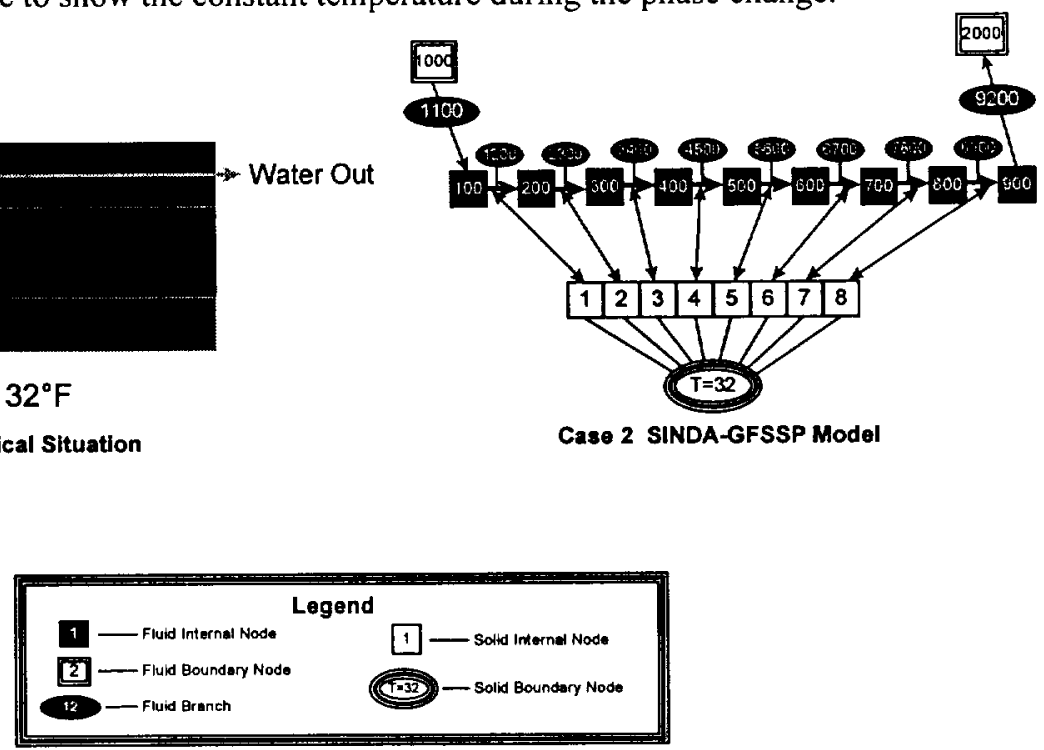

Figure 6: Test Case Two - Physical Situation and Combined Models 


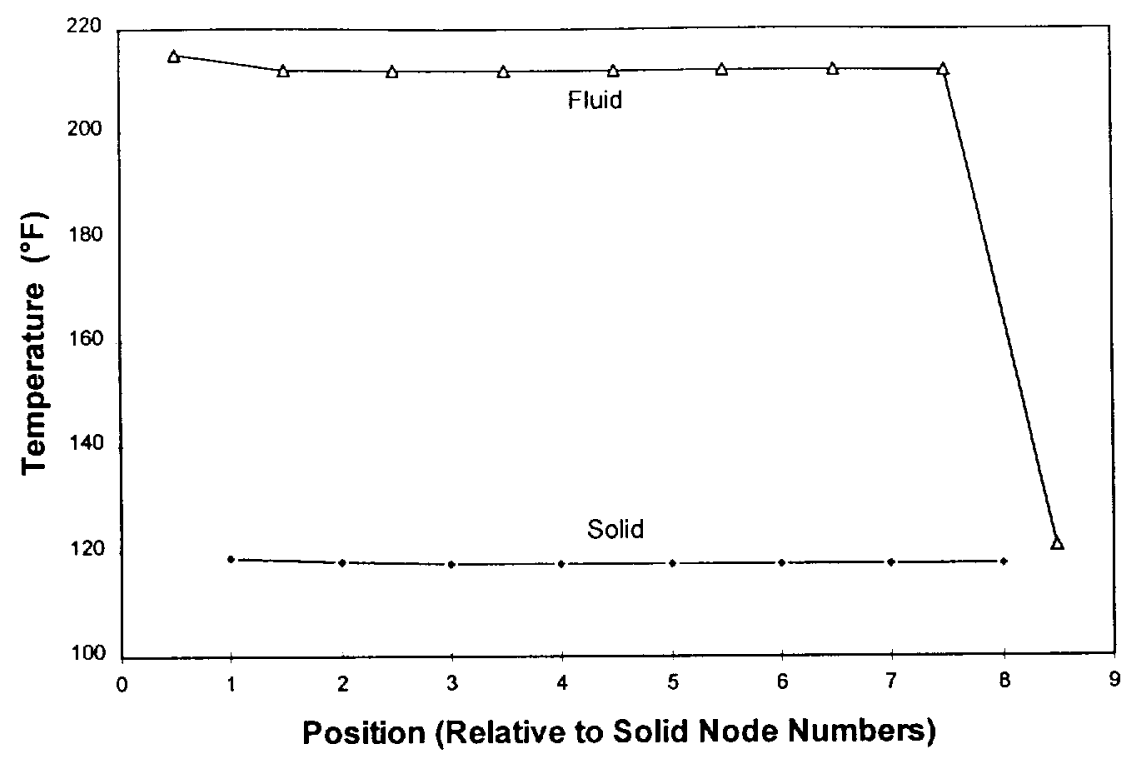

Figure 7: Test Case Two - Temperature vs. Location for both Solid \& Fluid Models

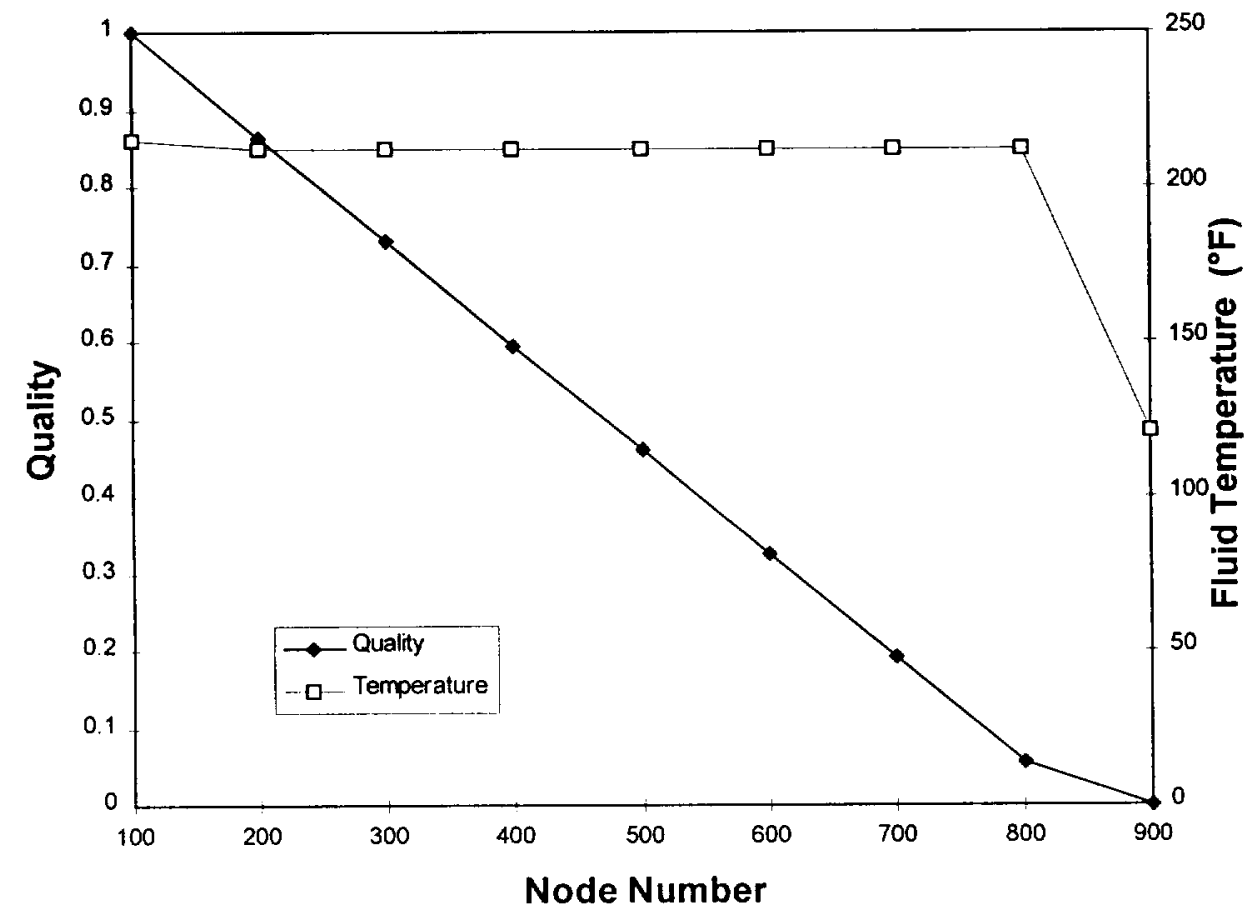

Figure 8: Test Case Two - Fluid Quality vs. Location

The goal of the second of the additional test cases (the third test case) was to control the area of an orifice using a temperature supplied by SINDA/G. In this case, a metal bar is bounded by two fluid streams (one cold, the other hot) in steady state operation as illustrated in Figure 9, below. The bar is 0.25 feet thick, with a thermal conductivity of $18.8 \mathrm{BTU} / \mathrm{ft}-\mathrm{hr}{ }^{\circ} \mathrm{R}\left(5.22 \times 10^{-3} \mathrm{BTU} / \mathrm{ft}-\mathrm{sec}^{\circ} \mathrm{R}\right)$. The bar has been descretized into 35 solid nodes. The cold fluid stream consists of water entering at boundary node 1 with boundary conditions of $70^{\circ} \mathrm{F}$ and $45.5 \mathrm{psia}$, and exiting at boundary node 8 with a boundary pressure of $45.0 \mathrm{psia}$. 
The cold stream entrance branch (branch 12) is an orifice with a cross-sectional area of 0.25 square inches and loss coefficient of 0.6 . The remainder of the cold stream has a cross-sectional area of 0.5 square inches. The hot stream consists of steam entering at boundary node 11 with boundary conditions of $250^{\circ} \mathrm{F}$ and 14.75 psia, and exiting at boundary node 18 with a boundary pressure of 14.70 psia. The hot stream entrance branch (branch 1112) is an orifice whose area is a function of the temperature of the adjacent solid node (node 105). The functional relationship between the orifice cross-sectional area and solid node temperature is provided in Equation 2, below.

$$
\begin{aligned}
& \mathrm{A}_{\text {Orifice }}=0.15+\left[0.01 *\left(\mathrm{~T}_{\text {solid }}-155.0\right)\right] \\
& \text { where, } \quad \mathrm{A}=\text { Area in square inches } \\
& \mathrm{T}=\text { Temperature in }{ }^{\circ} \mathrm{F}
\end{aligned}
$$
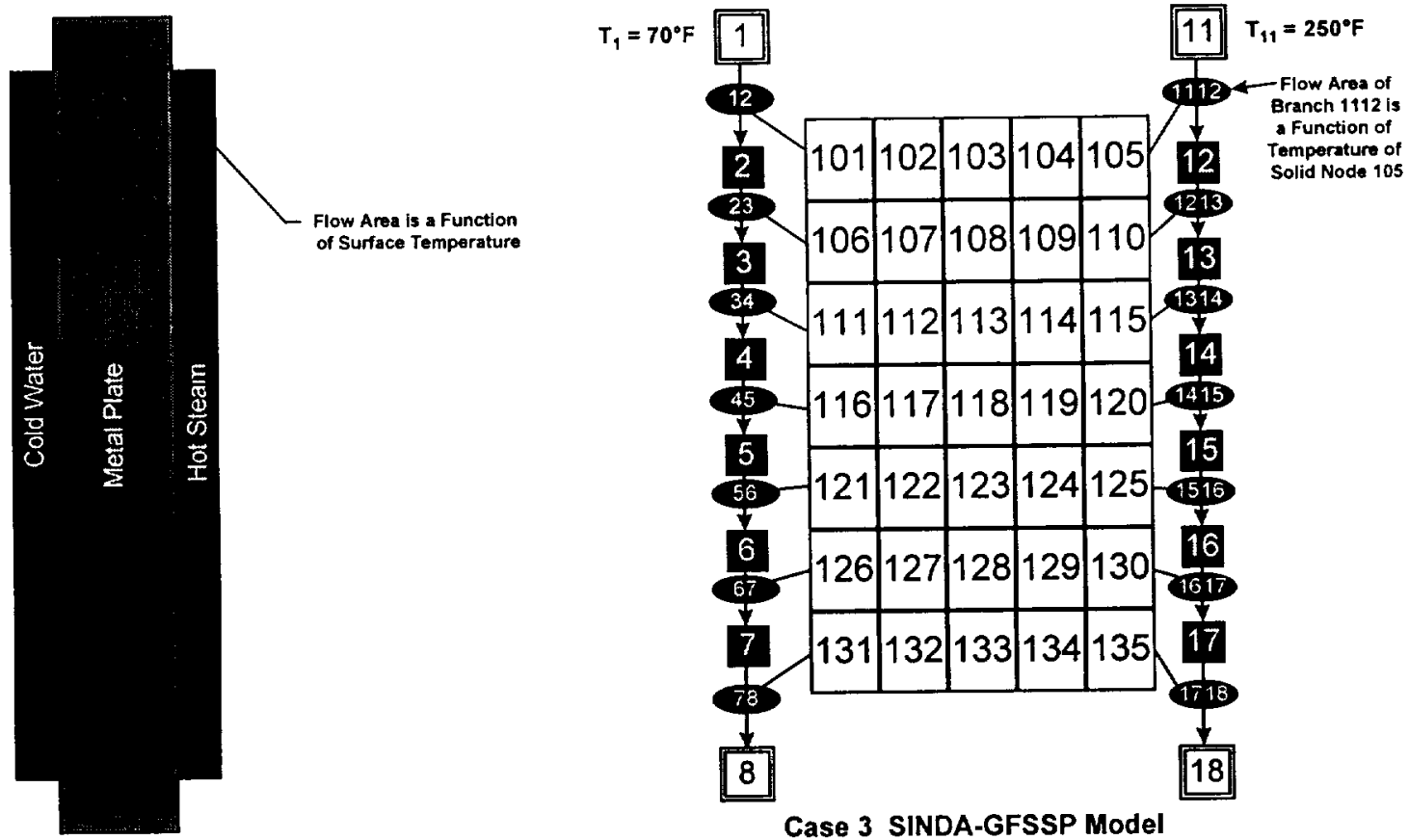

Physical Situation

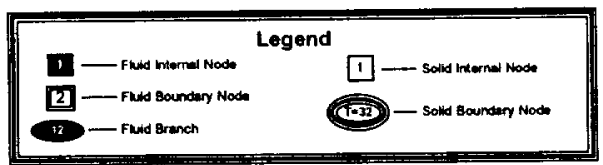

Figure 9: Test Case Three - Physical Situation and Combined Models

For simplicity, the heat transfer coefficient for each stream was set at a constant value: $5.0 \times 10^{-3}$ $\mathrm{BTU} / \mathrm{ft}^{2} \mathrm{sec}^{\circ} \mathrm{R}$ for the cold stream and $2.5 \times 10^{-3} \mathrm{BTU} / \mathrm{ft}^{2} \mathrm{sec}^{\circ} \mathrm{R}$ for the hot stream. The results of the modeling effort for case 3 are shown in Figures 10 and 11. Figure 10 illustrates the temperature profile in the bar at the fluid entrance location (solid nodes 101-105), midline (solid nodes 116-120) and fluid exit location (solid nodes 131-135). Figure 11 illustrates the convergence characteristics of the area for fluid branch 1112 as a function of the solid model iteration. 


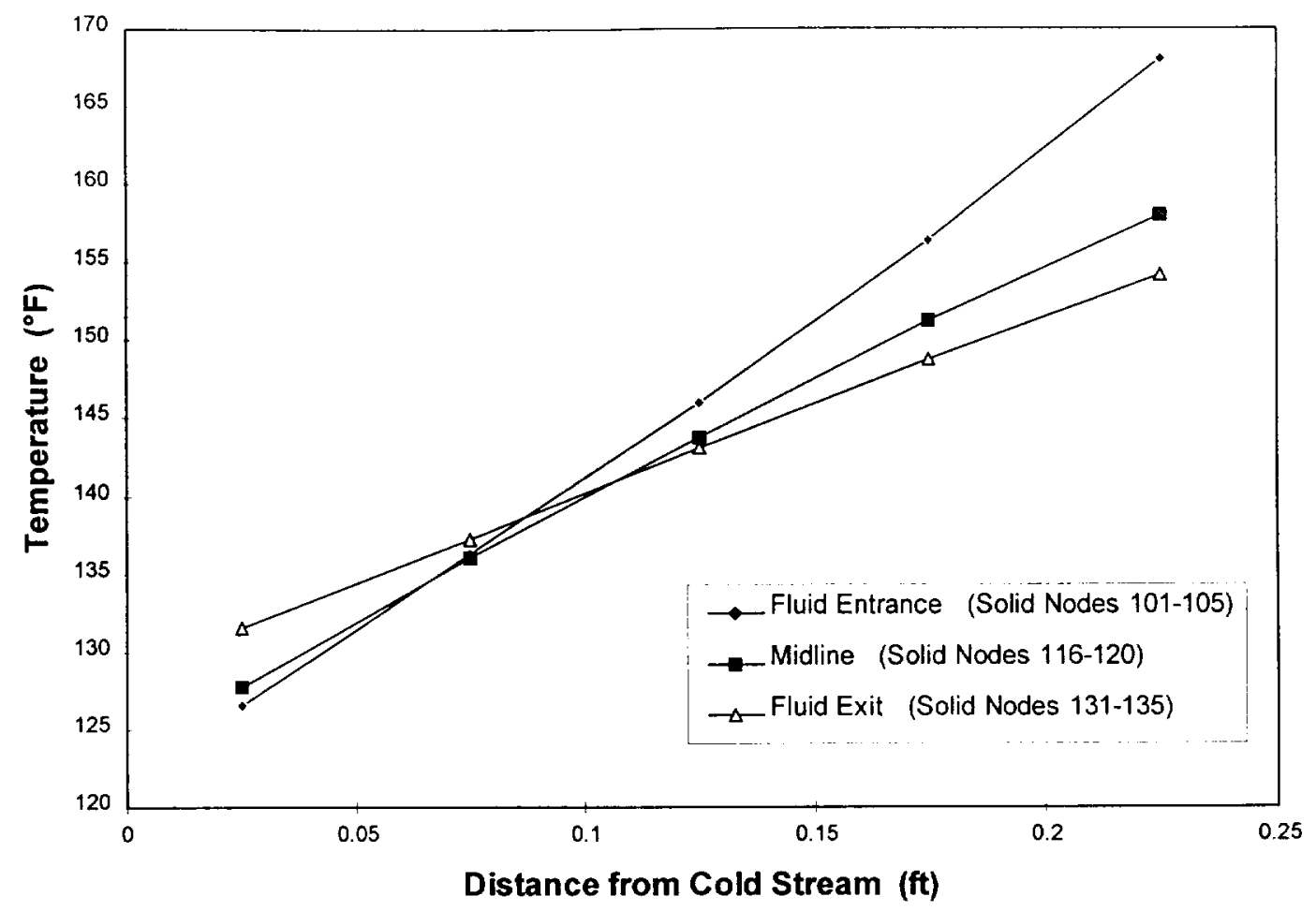

Figure 10: Test Case Three - Temperature Profile in the Solid at Three Locations

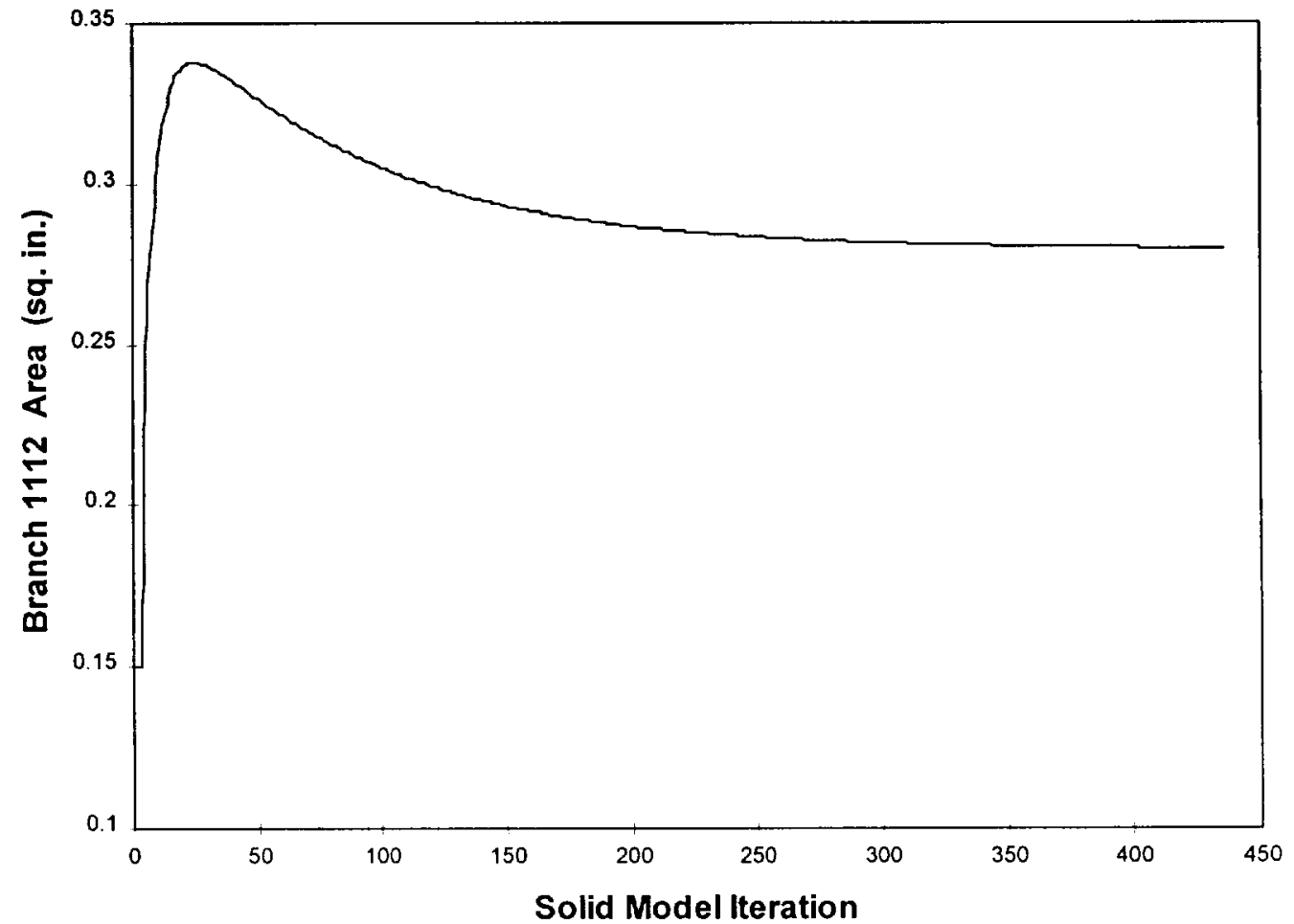

Figure 11: Test Case Three - Fluid Branch 1112 Orifice Area vs. Solid Model Iteration 
The final additional test case (test case four) had the goal of a "quasi-steady" operation in which the SINDA model is run in an unsteady mode, and the time step controls the boundary conditions of the fluid loop operating in steady state mode. The physical situation modeled is nearly identical in geometry to test case three, except that the fluid networks' geometries remain constant (i.e. area of branch 1112 is 0.15 in $^{2}$ and not a function of the temperature of solid node 105). The metal bar is initially at an uniform temperature of $155^{\circ} \mathrm{F}$. The cold fluid stream boundary node 1 is initially at $70^{\circ} \mathrm{F}$ and 45.5 psia; whereas, the cold fluid stream boundary node 8 pressure is set at 45.0 psia. The hot fluid stream boundary node 11 is initially at $250^{\circ} \mathrm{F}$ and 14.75 psia; whereas, the hot fluid stream boundary node 18 pressure is set at 14.70 psia. The thermal conductivity and convective heat transfer coefficients are the same as used in test case three. The total model run time is 20 hours, with the first 10 hours used to establish a steady state prediction. After 10 hours, the inlet temperature of the two fluid boundary nodes (fluid nodes 1 and 11 ) become a function of time. Equations 3 and 4 provide the functional relationship between temperature and time for fluid nodes 1 and 11 , respectively. Figure 12 illustrates the physical situation and combined models.

$$
\begin{aligned}
& \mathrm{T}_{1}=\left\{\begin{array}{c}
70^{\circ} \mathrm{F} \\
10 \mathrm{t}\left({ }^{\circ} \mathrm{F}\right)
\end{array}\right. \\
& \mathrm{T}_{11}=\left\{\begin{array}{c}
250^{\circ} \mathrm{F} \\
280-4 \mathrm{t}\left({ }^{\circ} \mathrm{F}\right)
\end{array}\right.
\end{aligned}
$$

$$
\text { where, } \mathrm{T}=\text { Temperature in }{ }^{\circ} \mathrm{F}
$$
$\mathrm{t}=$ time in hours
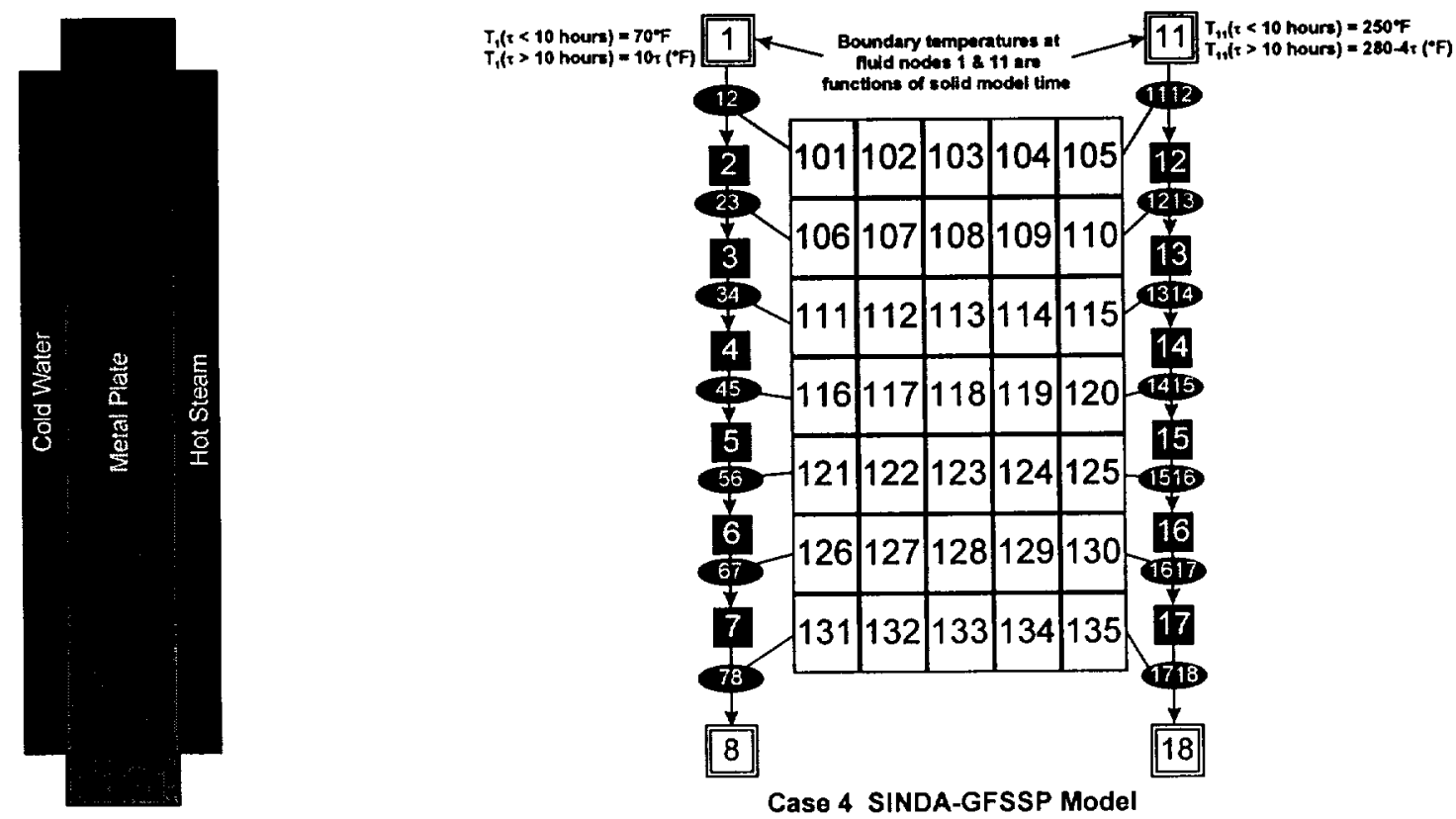

Physical Situation

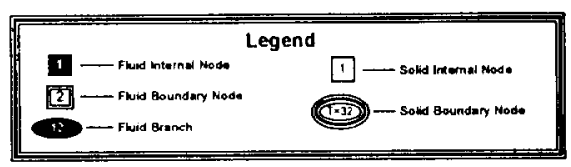

Figure 12: Test Case Four - Physical Situation and Combined Models 
The results of the modeling effort for case 4 are shown in Figures 13 and 14 . Figure 13 illustrates the temperature/time profile for three solid nodes $(116,118$, and 120) and the two inlet fluid boundary nodes. Figure 14 illustrates the temperature profile in the bar for solid nodes $116-120$ at several time steps These figures illustrate the solid temperature following the inlet fluid temperature.

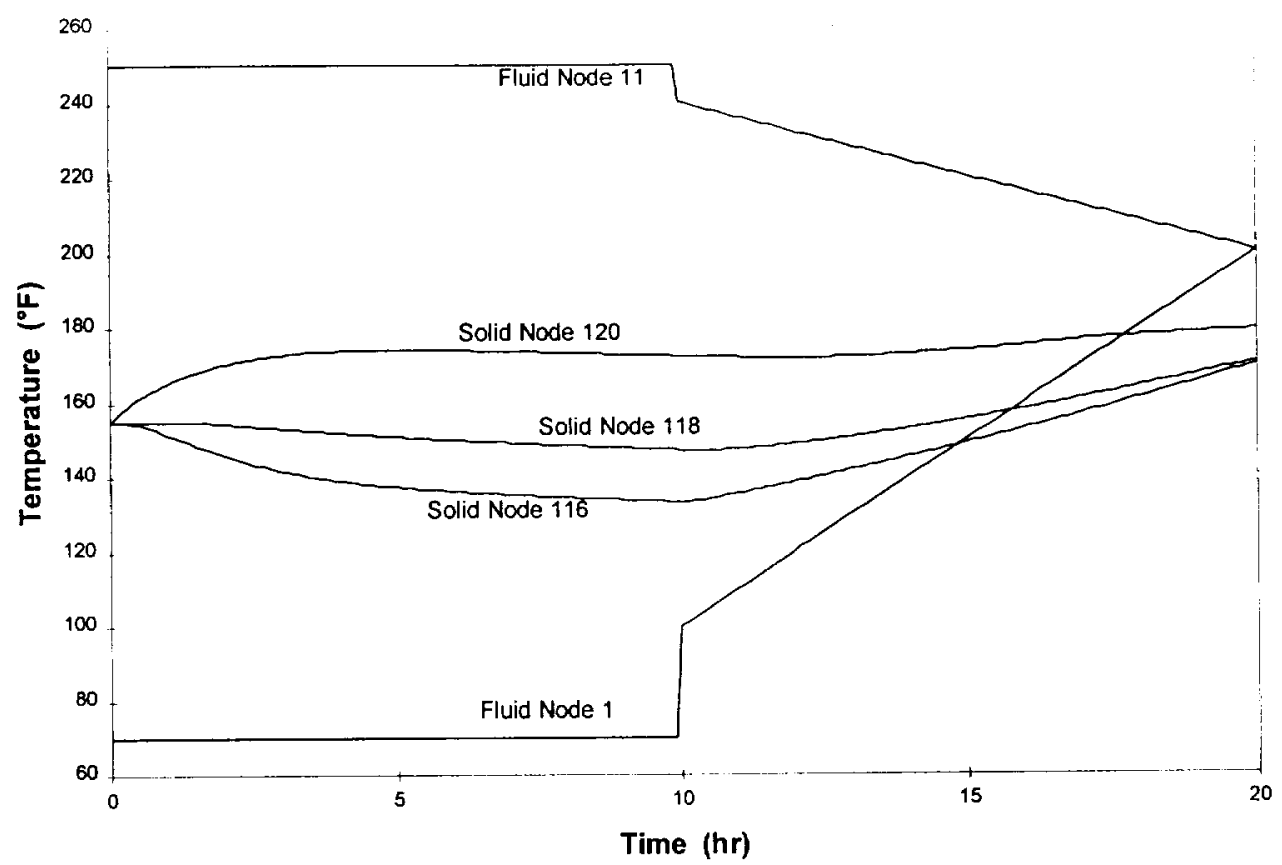

Figure 13: Test Case Four - Temperature vs. Time

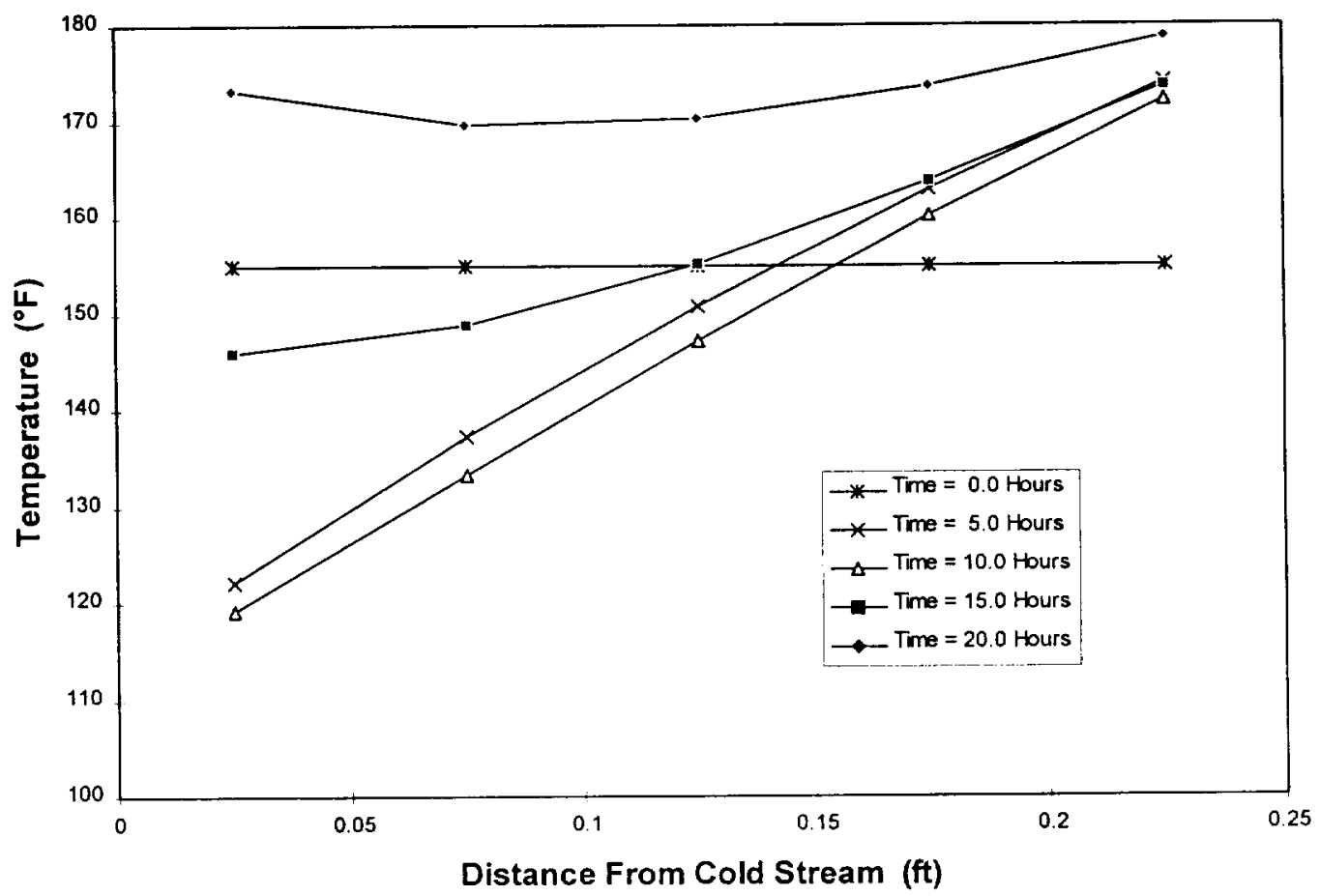

Figure 14: Test Case Four - Midline Temperature Profile 


\section{IMPLEMENTATION STATUS}

To date, the interface subroutine has been developed to allow for modeling of steady state flow networks with steady or unsteady solid modeling. Development is currently underway for fully unsteady modeling in which the time step for the fluid model may be different than that of the solid model.

\section{CONCLUSIONS}

A general purpose fluid network code has successfully been interface with a general purpose thermal analysis code for steady state flow models and both steady and unsteady thermal models. A benchmark case was identified, combined models were constructed and executed. The predictions from the combined benchmark models provided an accurate prediction of the temperature profile in the solid when compared to the analytical, closed form solution. Three additional cases demonstrated fluid phase prediction and control of the fluid model by the solid model's information via the interface subroutine. A status of the implementation was also provided.

\section{ACKNOWLEDGEMENTS}

The authors wish to thank Dr. Alok Majumdar of Sverdrup Technology for his help in the development of the interface subroutine. Additionally, the authors with to acknowledge the contributions of Dr. Barry Battista and Mr. Randy Lycans of Sverdrup Technology.

The majority of this work was performed by Sverdrup Technology personnel for the George C. Marshall Space Flight Center under contract NAS8-40386, Task Directive 661-007 with Mr. Bruce Tiller as the Task Initiator.

\section{REFERENCES}

1. Behee, R.: SINDA/G User's Guide, Version 1.81, Network Analysis, Inc., 1998.

2. Majumdar, A.K.; Bailey, J.W.; Schallhorn, P.A.; Steadman, T.: A Generalized Fluid System Simulation Program to Model Flow Distributions in Fluid Networks, (User's Manual) SvT Report No. 331-201-97-005, NASA MSFC Contract No. NAS 8-40836, October 1997.

3. Patankar, S., Numerical Heat Transfer and Fluid Flow, Hemisphere Publishing Co., New York, 1980.

4. Patankar, S., Karki, K., Documentation of COMPACT-2D Version 3.1, (User's Manual) Innovative Research, Inc., 1993.

5. Owen, J.W. (ed.): Thermal Analysis Workbook, NASA TM-103568, p.1-3-2, January 1992. 